\title{
Advances in The Therapy of Depression
}

\section{Editorial}

\section{Ghassan Haddad*}

Serhal Hospital, Lebanon

*Corresponding author: Ghassan Haddad, Serhal Hospital, Lebanon

Submission: July 04, 2018; Published: 曲 July 06, 2018

\section{Editorial}

Depression is one of the most common serious medical and psychiatric disorders, with greater than 200 million adults worldwide suffering from major depressive disorder (MDD) at any given time, according to a 2003 report by the World Health Organization titled Investing in Mental Health.

According to the U.S. National Comorbidity Survey Replication published in 2007, more than 16 million adults in the United States, which represents approximately $6.7 \%$ of itsentire adult population, will suffer from MDD in a 12-month period.

The quest to come up with a superior antidepressant is in full effect among biotech and pharmaceutical companies. Although there are some companies that are still tweaking various formulations

of serotonergic, noradrenergic, and dopaminergic substances i.e. triple reuptake inhibitors others are thinking outside the box.

Based on current research, the next decade of antidepressant development will likely be drugs that affect the opioid receptors specifically the kappa receptor (OPKR).

OPKR and their endogenous neuropeptide ligand, dynorphin A, are densely localized in limbic and cortical areas comprising the brain reward system and are both upregulated by stress.

Researchers have discovered that developing opioid receptor kappa (OPKR) antagonists may work extremely well for the treatment of major depression. OPKR provides an antidepressant response without significantly increasing pleasure (as would be derived from stimulation of the opioid mu receptors(Figure 1).

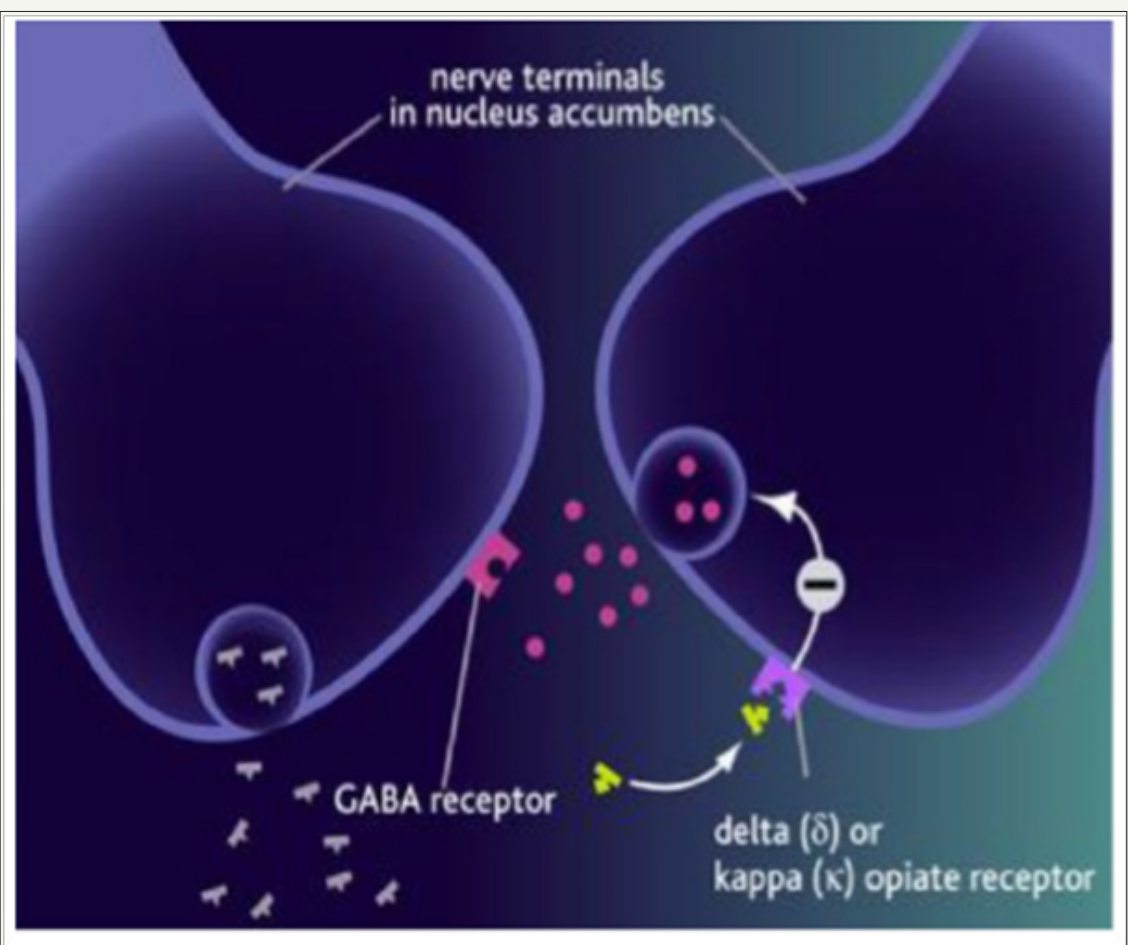

Figure 1. 
New Kappa Opioid Receptor Antagonists for Depression:

\section{A. ALKS-5461}

Of all kappa-receptor antagonists in development, this is perhaps the most exciting. It combines a drug that alleviates depression (Buprenorphine) with another drug (Samidorphan) which negates any significant pleasure response by selective antagonism of the mu-receptor. The early stages of clinical trials are promising, so much so that the FDA granted it fast track designation. Many people with depression find that antidepressants alone are unable to adequately address all of their symptoms especially the depressed mood and lack of energy, the FORWARD-4 Study is set to address that, and result will soon be released.

\section{LY-2456302}

This is a new antidepressant in development by the company Eli Lily. They are developing a new kappa-opioid receptor antagonist drug with short-acting properties to serve as an adjunctive treatment for refractory forms of depression. Currently the drug is in Phase II clinical trials in the United States.LY-2456302 has been shown to elicit synergistic effects when combined with other antidepressants (e.g.SSRI and TCAs).

LY-2456302 now called CERC-501 is currently being evaluated by researchers at the Massachusetts General Hospital in Collaboration with the National Institute of Mental Health (NIMH) as an adjunct treatment option for those with "treatment-resistant" forms of depression.

This gives a patient the best-case scenario: an opioid-based antidepressant response without a risk of dependency.Another clinical trial is currently assessing the OPKR in mood and anxiety. The study is called FASTMAS (Fast-Fail Trials in Mood and Anxiety Spectrum Disorders.

Before the development of antidepressants, opioid agonists were used to treat depression. This practice was consistent with recent findings of depression-related dysregulation of the opioid receptor and with mood improvement in treatment-resistant depression after treatment with the mixed agonist/antagonist buprenorphine.

A current placebo-controlled study involving 32 depressed subjects who had failed a single antidepressant trial, researchers tested a medication combining an opioid agonist (buprenorphine, $8 \mathrm{mg}$ ) with an opioid antagonist (samidorphin). Compared with placebo, treatment at 1 week was associated with significantly greater and faster reductions in scores on a standardized depression rating scale and minimally increased euphoria scores. The active treatment was associated with mild dizziness and nausea.

CERC-501 will be available as monotherapy or adjuvant therapy with other first-line antidepressants in the treatment of Treatment resistant depression, if ongoing clinical trials continue to provide positive benefit-risk profiles.

Individuals that have taken Suboxon (an opioid replacement drug) know that it works pretty well at eliciting an antidepressant response. In fact, it tends to work so well that individuals who are classified as having treatment-resistant depression often are able to get significant relief with Suboxone. From a medical perspective, the major problem with using Suboxone to treat depression is that it affects the mu-opioid receptor, resulting in pleasurable effects and potential dependency.

The STAR-D Report, $51.4 \%$ of patients failed to respond, defined as achieving a $50 \%$ reduction in symptoms, and only $36.8 \%$ became symptom free, or achieved remission, after their initial 12week. New extensive researches might bring more drug candidates targeting the endogenous opioid system to clinical trials to address current challenges in MDD treatment in clinical practice.For suicidal patients and for patients with treatment resistant depression OPKR antagonists brings new hope.
Creative Commons Attribution 4.0 International License

For possible submissions Click Here
Submit Article

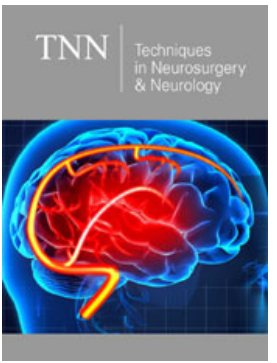

\section{Techniques in Neurosurgery \& Neurology}

\section{Benefits of Publishing with us}

- High-level peer review and editorial services

- Freely accessible online immediately upon publication

- Authors retain the copyright to their work

- Licensing it under a Creative Commons license

- Visibility through different online platforms 